Check for updates

Cite this: RSC Adv., 2019, 9, 19729

Received 1st April 2019

Accepted 15th June 2019

DOI: $10.1039 / \mathrm{c} 9 \mathrm{ra02441g}$

rsc.li/rsc-advances

\section{Conversion of woody oil into bio-oil in a downdraft reactor using a novel silicon carbide foam supported MCM41 composite catalyst}

\author{
Zhenting Yu, ${ }^{a b}$ Yunpu Wang, (DD *ab Lin Jiang, ${ }^{a b}$ Leilei Dai, ${ }^{a b}$ Yuhuan Liu, ${ }^{a b}$ \\ Roger Ruan, ${ }^{a b c}$ Pingwei Wen, ${ }^{a b}$ Yunfeng Zhao, ${ }^{a b}$ Dengle Duan, ${ }^{\text {abd }}$ Rongge Zou, ${ }^{a b}$ \\ Qiuhao $W u^{\text {ab }}$ and Yanzhi Lib
}

\begin{abstract}
This study reports the synthesis of a SiC-MCM41 composite catalyst by a microwave-assisted hydrothermal process and the composite catalyst had the characteristics of MCM41 and SiC, and the surface of SiC grew evenly with a layer of MCM41 after characterization of the catalysts by various means (X-ray diffraction, Brunauer-Emmett-Teller, scanning electron microscopy). The catalyst was applied in the pyrolysis of waste oil to investigate how it influences the bio-oil component proportion compared with no catalyst, only SiC, only MCM41 catalysis and the catalytic effect was also investigated at different temperatures and different catalyst to feed ratios. In a downdraft system with a pyrolysis temperature of $550{ }^{\circ} \mathrm{C}$, a catalyst to feed ratio of $1: 2$, and a catalytic temperature of $400{ }^{\circ} \mathrm{C}, 32.43 \% \mathrm{C}_{5}-\mathrm{C}_{12}$ hydrocarbons and $41.10 \%$ monoaromatics were obtained. The composite catalyst combined the catalytic effect of SiC and MCM41 because it increased the amount of $\mathrm{C}_{5}-\mathrm{C}_{12}$ hydrocarbons and decreased the amount of oxygen-containing compounds in bio-oil. After repeated uses, the composite catalyst still retained the catalytic properties.
\end{abstract}

\section{Introduction}

Owing to the potential problems of waste oil treatment, such as hazards to the human health and the environment, research on the conversion of waste oil into biodiesel has developed rapidly in recent years. ${ }^{1}$ As environmental awareness increases and petroleum reserves decrease, biodiesel as an alternative resource to alleviate the problem of resource shortage has promising prospects. ${ }^{2}$ Waste oil can be exploited for making diesel fuel and be used as a possible candidate for the precursor of biodiesel. ${ }^{3,4}$

Methods like pyrolysis, gasification, hydrocracking reactions and catalytic cracking can convert vegetable oil into biofuels. ${ }^{5}$ In recent years, fast pyrolysis has been combined with microwave irradiation which could reduce the energy usage, heat loss and the production cost. ${ }^{6-9}$ Also, microwave pyrolysis could avoid the undesired second cracking during the long reaction time in conventional pyrolysis. ${ }^{10}$ However, the limited use of the microwave pyrolysis of biomass is owing to the liquid product's

${ }^{a}$ State Key Laboratory of Food Science and Technology, Nanchang University, Nanchang, Jiangxi, 330047, China

${ }^{b}$ Engineering Research Center for Biomass Conversion, Ministry of Education, Nanchang University, 235 Nanjing East Road, Nanchang, Jiangxi, 330047, China. E-mail: wangyunpu@ncu.edu.cn

${ }^{c}$ Center for Biorefining and Department of Bioproducts and Biosystems Engineering University of Minnesota, 1390 Eckles Ave., St. Paul, MN 55108, USA

${ }^{d}$ Department of Biological Systems Engineering, Washington State University, 2710 Crimson Way, Richland, WA 99354, USA low quality such as low heating value, high acidity, thermal instability. ${ }^{11}$ When microwave pyrolysis combines with catalyst, the additional upgrading process can overcome these problems. At the same time, different catalyst presence different selectivity which can varies the composition of the product. ${ }^{5}$ Scientific literatures have been reported that the mesoporous molecular sieves (MCM41) possess a large surface areas and uniform hexagonal channel arrangement which can provide more accessible reaction sites in contrast with microporous molecular zeolites (HZSM-5). ${ }^{\mathbf{1 2 , 1 3}}$ Researchers found that the MCM41 which is the mesoporous catalyst with relatively large pores and mild acidity can crack the large oxygenated compounds into small molecules. ${ }^{\mathbf{1 4 , 1 5}}$

In this study, a composite catalyst of the MCM41 coating on the SiC foam ceramics (SiC) is developed to applied in the microwave-assisted pyrolysis. Owing to silicon carbide's stable tetrahedral structure constructed by carbon and silicon atom, it is not easy to load metal active components, the development of serving silicon carbide as catalyst and catalyst support was limited. After studying the zeolite membrane's characteristic and new processes of preparing porous $\mathrm{SiC}$, an attractive method was put forward - forming the mesoporous molecular sieve on the surface of the porous SiC support - this composite catalyst contains both the catalysis, adsorption, selection of 1 the molecular sieve and the chemical stability, good thermal conductivity, high mechanical strength of the silicon carbide. ${ }^{16-18}$ In our previous study, the SiC performed the function of promoting the yield of aromatics in bio-oil. ${ }^{19}$ Both 
SiC and MCM41 decreased the yield of the pyrolysis oil and increased the gas product. ${ }^{20}$ Combining these two kinds of catalysts, how the composite catalyst will affect the product distribution and the composition of liquid product is worth to investigate.

The objectives of this paper were to synthesis the SiCMCM41 composite catalyst and investigate the effect of the catalyst on the product distribution and the composition of liquid product during the microwave pyrolysis. The composite catalyst SiC-MCM41 was characterized by X-ray diffraction (XRD), Brunauer-Emmett-Teller (BET), scanning electron microscopy (SEM) technologies. The influence of the type of catalyst, the catalytic temperature and the ratio of catalyst to feed on the mass yield and the characteristics of pyrolysis oil were investigated. The chromatography-mass spectrometry (GCMS) and Fourier-transform infrared (FTIR) spectroscopy were used to determine the chemical composition and the functional group changes of the pyrolysis oil. The variation of the yield and the chemical composition of the pyrolysis oil would be compared to exam the stability of the catalyst after repeated use.

\section{Material and methods}

\subsection{Material}

The Sapium sebiferum kernel oil, which was used as the raw material of the pyrolysis, was obtained from Jiujiang, Jiangxi in China. The elemental composition of the Sapium sebiferum kernel oil was determined as follows: $43.02 \% \mathrm{C}, 5.34 \% \mathrm{H}$, $2.56 \% \mathrm{~N}$, and $44.83 \% \mathrm{O}$. The fatty acids composition of the material is listed in Table 1 . The SiC foam ceramics were purchased from Yi Fang Co., Ltd (Laiwu, China). The foam ceramics were cut into small pieces of an average size $(10 \mathrm{~mm} \times$ $10 \mathrm{~mm} \times 10 \mathrm{~mm}$ ) in order to fit into the quartz catalytic reactor. They are used as base material for the composite catalyst. The microwave absorbent silicon carbide particles with a diameter of $5 \mathrm{~mm}$ were purchased from the Yike Co., Ltd (Shenzhen, China).

\subsection{Catalyst}

2.2.1 Catalyst preparation. The MCM41 was coated on the surface of silicon carbide by microwave hydrothermal synthesis. The synthesis of composite catalysis combines the synthesis steps of Men et al. ${ }^{21}$ and microwave conditions of Krittanun et al. ${ }^{22}$

First, the SiC foam ceramics was calcined in the muffle furnace in $550{ }^{\circ} \mathrm{C}$ calcination for $4 \mathrm{~h}$ to form a densified membrane on the surface.

According to the mole ratio of 1 tetraethylorthosilicate (TEOS, $28 \%$, Damao Chemical reagent plant) $/ 0.2$ hexadecyl trimethyl

Table 1 Relative proportion (area\%) of the main components in the tallow kernel oil

\begin{tabular}{llc}
\hline Name & $\begin{array}{l}\text { Molecular } \\
\text { formula }\end{array}$ & Area\% \\
\hline Linoleic & $\mathrm{C}_{18} \mathrm{H}_{32} \mathrm{O}_{2}$ & 34.26 \\
Oleic & $\mathrm{C}_{18} \mathrm{H}_{34} \mathrm{O}_{2}$ & 25.25 \\
Palmitic & $\mathrm{C}_{16} \mathrm{H}_{32} \mathrm{O}_{2}$ & 23.91 \\
Linolenic & $\mathrm{C}_{18} \mathrm{H}_{30} \mathrm{O}_{2}$ & 16.67
\end{tabular}

ammonium bromide (CTMAB, 99\%, Aladdin)/160 deionized water, a precursor gel was prepared. The above mentioned amount of hexadecyl trimethyl ammonium bromide is dissolved in water, then the tetraethylorthosilicate solution slowly drip into the hexadecyl trimethyl ammonium bromide in aqueous solution, stirring for 5 minutes to mixing well. Using sodium hydroxide solution $\left(0.5 \mathrm{~mol} \mathrm{~L}^{-1}\right)$ to adjust $\mathrm{pH}$ to 10 , stirring until white precipitation appeared, the crystallization period took about $15 \mathrm{~min}$.

The calcined SiC foam ceramics and precursor gels are mixed at $1: 1$ by mass fraction, the mixture was transferred into the Teflon reaction kettle and closed, the Microwave MDS-6G (SINEO) reactor first heated with a heating rate of $5{ }^{\circ} \mathrm{C} \mathrm{min}^{-1}$ and then kept the temperature of $100{ }^{\circ} \mathrm{C}$ for 90 minutes. The microwave synthesizer has a frequency of $2450 \mathrm{MHz}$ and an output power of $1800 \mathrm{~W}$.

After the synthesis reaction, the composite catalysts were cooled at room temperature, filtered, washed to neutral with distilled water, and placed in the oven in $120^{\circ} \mathrm{C}$ for $12 \mathrm{~h}$ to dry volatile matter. After drying, unburned samples was calcined in the muffle furnace $550{ }^{\circ} \mathrm{C}$ for $6 \mathrm{~h}$. During calcinations, mesoporous material undergoes further condensation, CTAB and polymer are removed. The same procedure was applied to synthesis MCM41 except the addition of SiC to investigate the catalysis of the MCM41. In order to distinguish between composite catalysts and physically mixed catalysts, SiC-MCM41 is used to represent composite catalysts and SiC/MCM41 is used to represent physically mixed catalysts. The loading rate determined the mixing weight of MCM41 and SiC for physical mixed catalysts.

2.2.2 Catalyst characterization. The load rate of the MCM41 zeolites on the surface of SiC foam ceramics is quality difference before and after loading MCM41 on silicon carbide divided by silicon carbide.

$\mathrm{XRD}$ measurements were performed by a multi-function $\mathrm{X}$ ray diffractometer (BEDE/D1) in the range of $2 \theta$ from $1^{\circ}$ to $80^{\circ}$ with a scanning step of $5^{\circ} \mathrm{min}^{-1}$ which was used to measure the characteristic peaks of different catalysts and physical phase retrieval of composite catalyst. The BET were acquired using BK132F to obtain the specific surface area, pore volume and pore diameter of different catalysts. The SEM images were collected on JSM-6701F (JEOL) and the microstructure like morphology and the surface structure of the SiC and the composite catalyst can be observed. Due to the unconductivity of silicon carbide, the catalyst was pretreated with gold coating. For the better observing of the surface morphology of catalysts, we chose the magnification factor of 35, 500, 5000, 10000.

\subsection{Experiment procedure}

The microwave-assisted pyrolysis was carried on a microwave oven (MAX, CEM Corporation) with a frequency of $2450 \mathrm{MHz}$ and power input of $600 \mathrm{~W}$. Fig. 1 shows the external catalytic pyrolysis system. The experimental device is the same as the one in the paper we published recently. ${ }^{19}$ The heated part is made of quartz material, which can resist the high temperature that pyrolysis required. For each run, approximately $500 \mathrm{~g}$ silicon carbide particles were used as the microwave absorbent to achieve rapid heating. Before reaction, the system was replenished with 


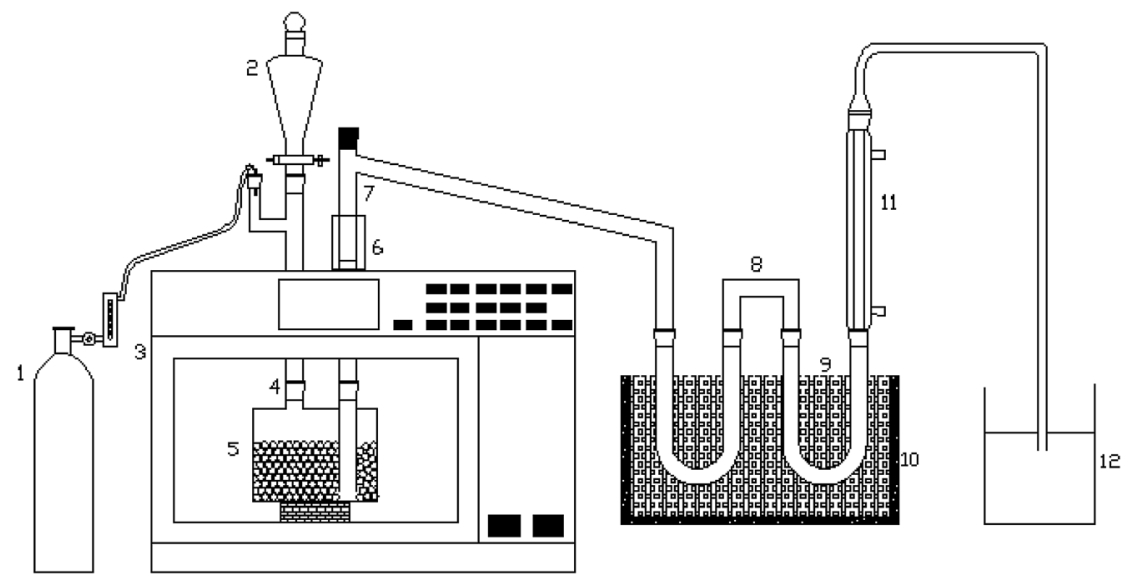

Fig. 1 Schematic diagram of external catalytic pyrolysis. The system is composed of: (1) nitrogen gas; (2) feed inlet; (3) microwave device; (4) quartz reactor; (5) microwave absorbent ( $\mathrm{SiC}$ ) bed; (6) electric heating jacket; (7) quartz connector; (8) U-type glass connection pipe; (9) condensate bottle; (10) tap water of $2{ }^{\circ} \mathrm{C}$; (11) condenser-west tube; (12) passing into water.

nitrogen gas at a flow rate of $0.81 \mathrm{~min}^{-1}$ for 5 min to maintain a stable reaction atmosphere. The oil $(10 \mathrm{~g}$ Chinese Sapium sebiferum kernel oil) with a feed rate of $1 \mathrm{ml} \mathrm{min}^{-1}$ was dripped into the downdraft system when the SiC bed and the external heating sleeve both reached the set temperature. The cracking reaction lasted 30 minutes, during the process, the microwave oven was turned on and off to keep a relatively stable temperature (vary at around $\pm 5^{\circ} \mathrm{C}$ ). When the pyrolysis finished, the nitrogen gas was passed through again with the same flow rate to expel the remaining gas in the quartz bottle. In order to ensure the accuracy of the experiment, each experiment would be repeated three times. The condensable component (bio-oil) was collected in the U-type vessel which was in $0{ }^{\circ} \mathrm{C}$ ice bath. The quantity of solid residues (char) was the weight change of the downdraft quartz bottle before and after the reaction, it was measured by electronic scale. The weight of coke was obtained by analytical balance according to the weight difference between the fresh and used catalyst. The yields of aforementioned three components were calculated based on their actual weight, and the gas yield was calculated by mass balance.

\subsection{Characterization of bio-oil}

The chemical composition of the bio-oil was determined by GCMS (Agilent 7890-5975C) technologies. The model of the column, the temperature programming and other configuration settings of the procedure was the same as the report we published. ${ }^{23}$ The changes in the functional groups of bio-oil under different conditions were characterized by the FTIR. The FTIR spectra were performed by Nicolet iS5 with a scanning frequency of 32 scans and wave number range of $400-4000 \mathrm{~cm}^{-1}$.

\section{Results and discussion}

\subsection{Catalyst characterization}

After microwave assisted hydrothermal synthesis, a white powder coating can be seen on the surface of SiC foam ceramics and the final loading of the MCM41 zeolites was $21.4 \mathrm{wt} \%$.
XRD patterns of three different catalysts were shown in Fig. 2. From the picture, when $2 \theta$ is larger than $10^{\circ}$, almost no peaks were observed in MCM41, however, there are more than four diffraction peaks $\left(1.92^{\circ}, 3.78^{\circ}, 4.17^{\circ}, 5.97^{\circ}, 6.42^{\circ}\right)$ in the small angle area, which are agree with the characteristic of MCM41. ${ }^{24,25}$ The XRD pattern of the SiC exhibits the characteristic peaks at $35.6^{\circ}, 60.0^{\circ}$ and $71.7^{\circ}$ which were also found in SiC-MCM41. Also, the peaks $\left(4.17^{\circ}, 5.97^{\circ}, 6.42^{\circ}\right)$ were found in the small angle area of the SiC-MCM41 which indicates the composite catalyst compounded well.

SEM shows the surface morphology of the $\mathrm{SiC}$ and the composite catalyst. From the Fig. 3 and 4, it can be observed that the surface of silicon carbide appeared regular pattern at 10000 times magnification while the surface of the composite catalyst was covered with massive MCM41. As the magnification decreased, the surface of silicon carbide gradually became smooth which was different with the composite catalyst. The composite catalyst can clearly observe the massive MCM41 at the 35 times magnification.

Table 2 shows the specific surface area, pore volume and pore diameter of different catalysts obtained by BET experiment. From the table, we can conclude that the pore diameter of MCM41 $(3.777 \mathrm{~nm})$ meets the mesoporous material standard that its pore diameter was between 2 and $50 \mathrm{~nm}$. The pore volume of the composite catalyst was similar to that of MCM41, both of which were around $0.2 \mathrm{~cm}^{3} \mathrm{~g}^{-1}$ while the pore diameter was closer to the $\mathrm{SiC}$ (34.452). The specific surface area of MCM41, SiC and SiC-MCM41 were 290.760, 2.250 and 17.623, respectively. These results showed that the composite catalyst was well developed and contained the properties of two catalysts.

\subsection{Analysis of pyrolysis product yield}

To compare different catalysts' product selection, three kinds of catalyst were performed in the downdraft reaction system. The catalytic temperature was held at $400{ }^{\circ} \mathrm{C}$ for both kinds of catalyst while the pyrolysis temperature was $550{ }^{\circ} \mathrm{C}$ to ensure the full cracking of Sapium sebiferum kernel oil and the catalyst 


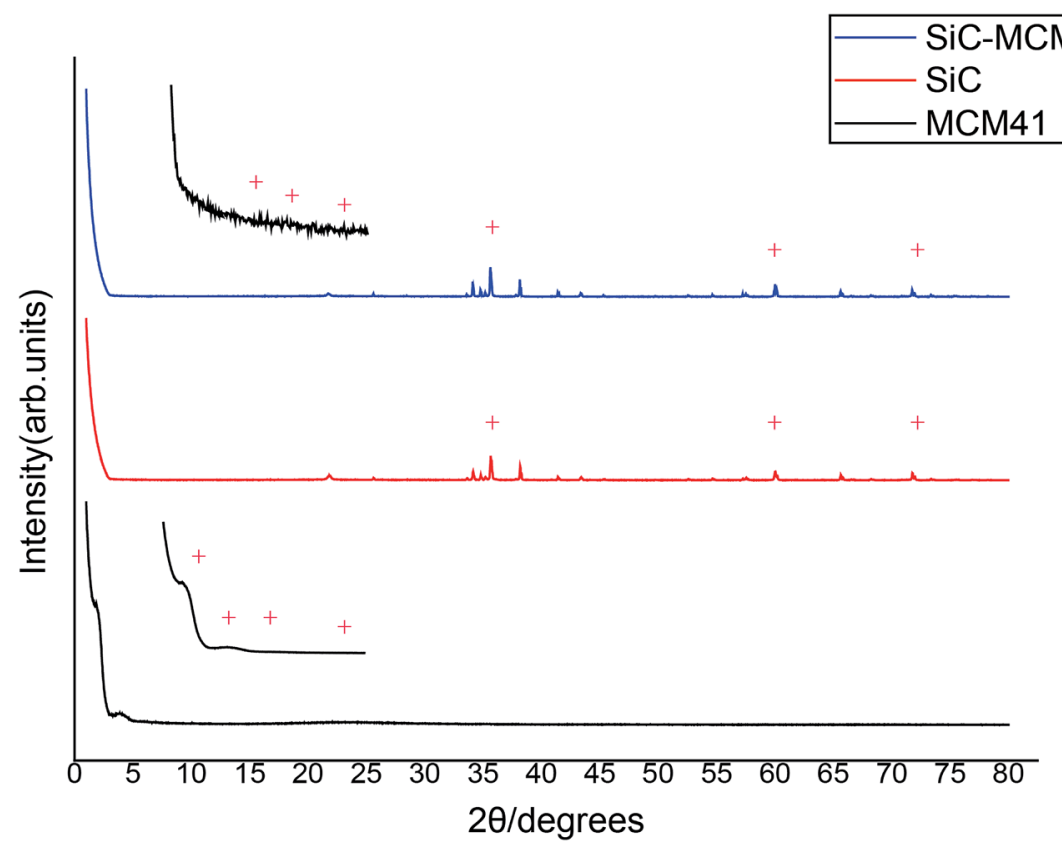

Fig. 2 XRD patterns of three different catalysts.

to feedstock ratio was $2: 1$. The effects of using different catalysts on product yield were presented in Fig. 5(a). As shown in Fig. 5(a), the addition of catalyst in the pyrolysis period decreased the bio-oil production and increased the gas production at a variable extent. Yu et al. ${ }^{25}$ has demonstrated that the mesoporous materials could promote the formation of gas and decreased the yield of liquid and char. Compared with nocatalyst, the production of bio-oil decreased from $79.31 \%$ to
$63.99 \%$ while the production of gas increased from $17.13 \%$ to $30.44 \%$, and the production of coke and tar increased slightly. The SiC catalyst and composite catalyst also showed similar catalytic results, but the catalytic decomposition was not as obvious as MCM41. This phenomenon appeared mainly due to more condensable oil vapors were converted into noncondensable gases under the catalysis of MCM41, more active substances were changed into hydrocarbons and carbon oxides

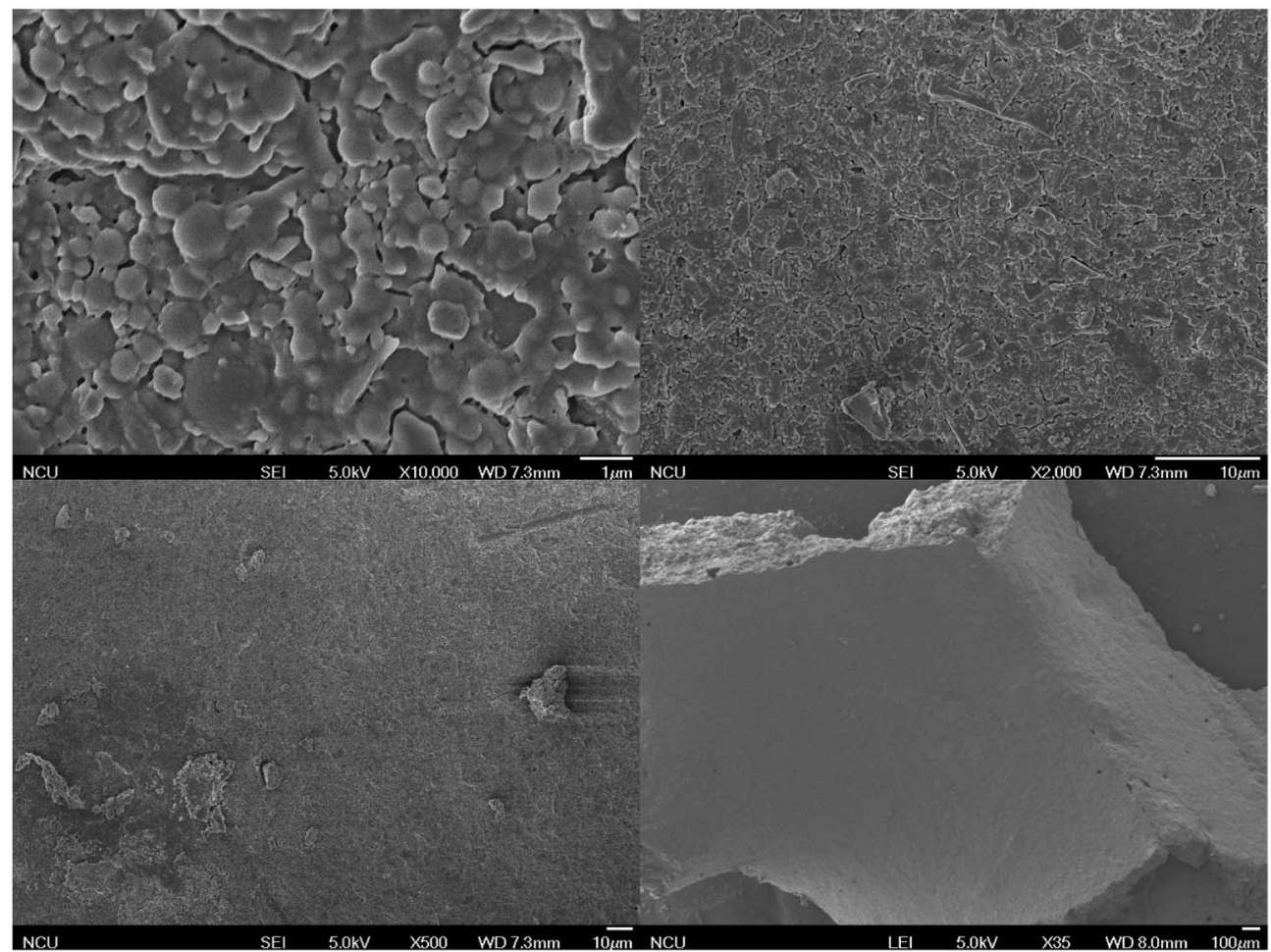

Fig. 3 SEM micrographs of SiC. 


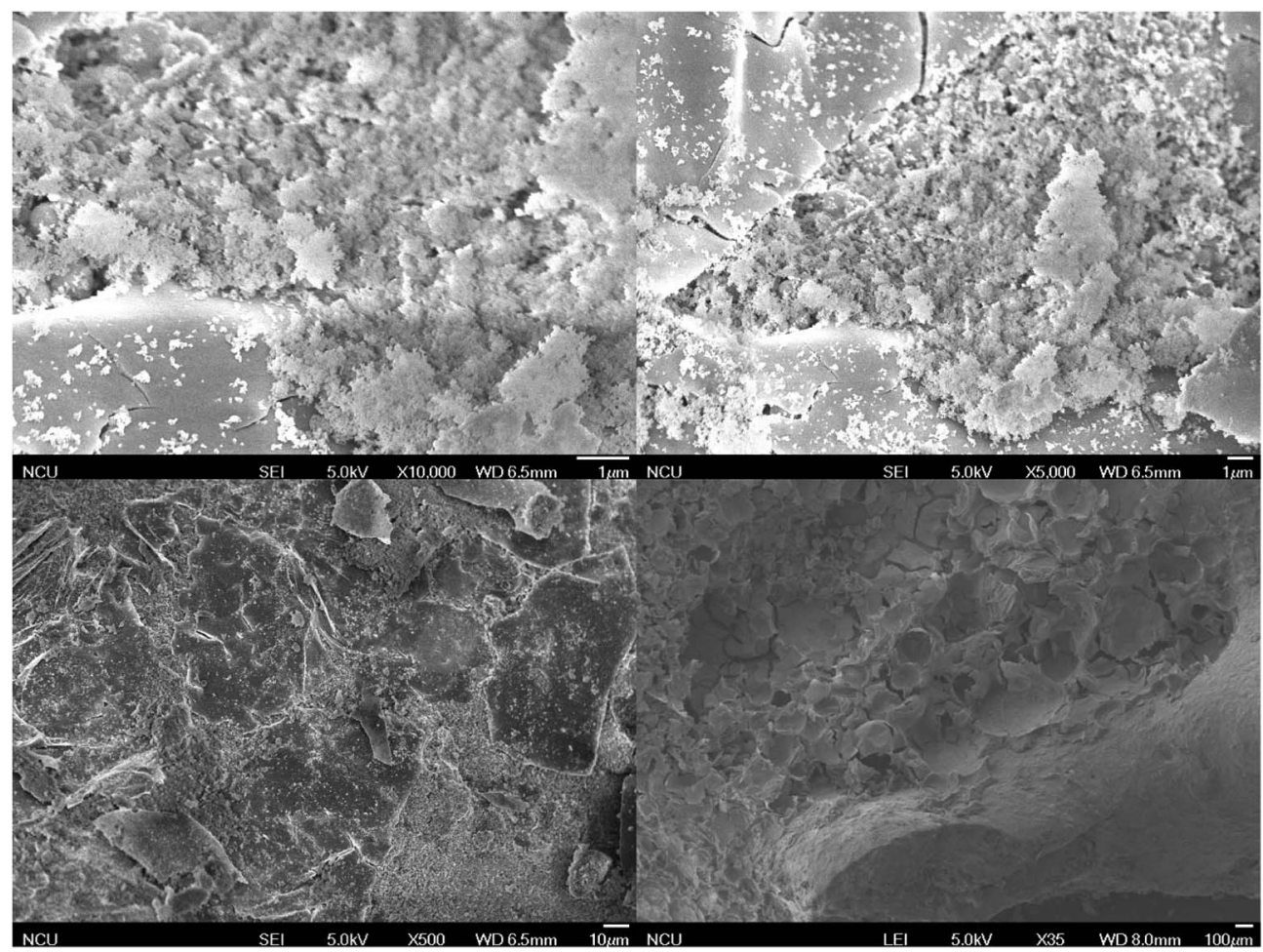

Fig. 4 SEM micrographs of regenerated SiC-MCM41 foam composite.

which matches with the findings before. ${ }^{26,27}$ The yield of bio-oil, char, coke, gas under the catalysis of SiC were $71.5 \%, 3.71 \%$, $0.76 \%$ and $24.03 \%$ respectively. In addition, Yu et al. have illuminated that the $\mathrm{SiC}$ catalysis could change the product composition by secondary cleavage in external heating jacket. ${ }^{19}$ Compared with non-catalyzed production of bio-oil, the bio-oil yield of SiC-MCM 41 catalyzed decreased by $4.52 \%$ and the gas yield increased by $3.31 \%$. Notably, there was no synergistic effect on the product yield under the catalysis of composite catalyst. However, the high yield of bio-oil under composite catalysis is satisfactory. The yield of bio-oil, char, coke, gas under the catalysis of SiC/MCM41 were $73.4 \%, 3.71 \%, 0.87 \%$ and $21.6 \%$ respectively. The product distribution of the mixed catalysts was quiet similar to that of SiC-MCM41.

To explore the effect of catalytic temperature on the SiCMCM41 composite catalyst's effect, the catalyst to feedstock ratio was set as $2: 1$. Product distribution under different catalytic temperature $\left(300{ }^{\circ} \mathrm{C}, 350{ }^{\circ} \mathrm{C}, 400{ }^{\circ} \mathrm{C}, 450{ }^{\circ} \mathrm{C}\right.$, and 500 ${ }^{\circ} \mathrm{C}$ ) is illustrated in Fig. 5(b). The bio-oil production fluctuates between 70 and $80 \%$, which is similar to the result of Xu et al. ${ }^{28}$ With the further increasing of the catalytic temperature, the bio-

Table 2 Physical parameters of the three catalysts by BET

\begin{tabular}{lcll}
\hline Catalysts & $\begin{array}{l}\text { Specific surface } \\
\text { area }\left(\mathrm{m}^{2} \mathrm{~g}^{-1}\right)\end{array}$ & $\begin{array}{l}\text { Pore volume } \\
\left(\mathrm{cm}^{3} \mathrm{~g}^{-1}\right)\end{array}$ & $\begin{array}{l}\text { Pore diameter } \\
(\mathrm{nm})\end{array}$ \\
\hline MCM41 & 290.760 & 0.241 & 3.777 \\
SiC & 2.250 & 0.028 & 34.089 \\
SiC-MCM41 & 17.623 & 0.206 & 34.452
\end{tabular}

oil yield decreased from $76.28 \%$ to $69.25 \%$ and the gas yield increased from $17.52 \%$ to $25.98 \%$. This phenomenon appeared because the increasing of the secondary cracking which facilitate the conversion from pyrolysis oil into incoagulable gas. ${ }^{29}$ The coke reduced from $2.27 \%$ to $1.18 \%$. According to the report of Duan et al., ${ }^{30}$ higher catalytic temperatures promote the decomposition of the long chain hydrocarbons and phenolic compounds, thus the number of the large molecules decreased and the light compound formed. In addition, the yield of char fluctuated but remained relatively stable. This result is consistent with the study reported by Fan et al. ${ }^{31}$ It explained the phenomenon that the char yield mainly was affected by the pyrolysis temperature but not catalytic temperature.

Effects of various catalyst to feed ratios $(2: 1,3: 2,1: 1,2: 3$, $1: 2$ ) on the product distribution were investigated. Catalytic temperatures were kept at $400{ }^{\circ} \mathrm{C}$. It can be observed that the char yield first gradually increased and reached its maximum $5.41 \%$ at the ratio of $1: 1$, because the pyrolysis vapors passed through the pores of catalyst particles and the carbonization reactions taken place..$^{32}$ By further observation, the bio-oil yield reduced (from $74.79 \%$ to $61.15 \%$ ) and the gas yield increased (from $19.44 \%$ to $32.208 \%$ ) with the increasing of the catalyst ratio, this phenomenon occurred because more catalyst aided the bio-oil cracking into gaseous compounds thus caused variation trend. ${ }^{30}$ During the ex situ pyrolysis process, a small amount of the coke (3.51-0.96\%) was obtained. With the decreasing of the catalyst to feedstock ratio, formation of the coke was hindered, because higher catalyst to feedstock ratio provided more locations for pyrolysis vapors to deposit on the

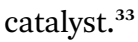


(a)

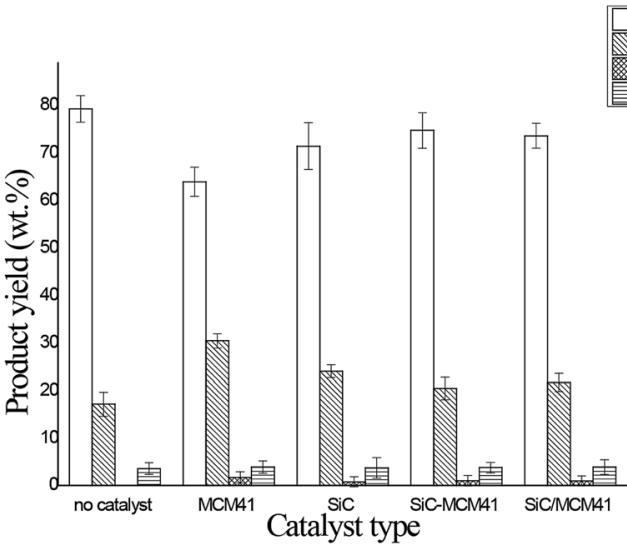

(b)

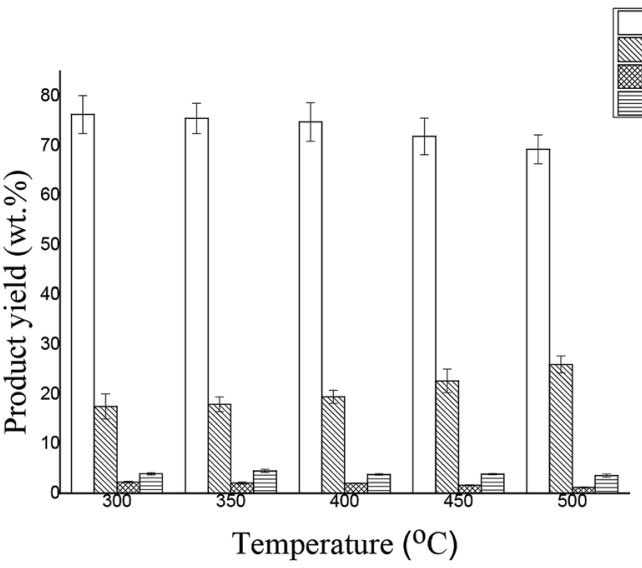

(c)

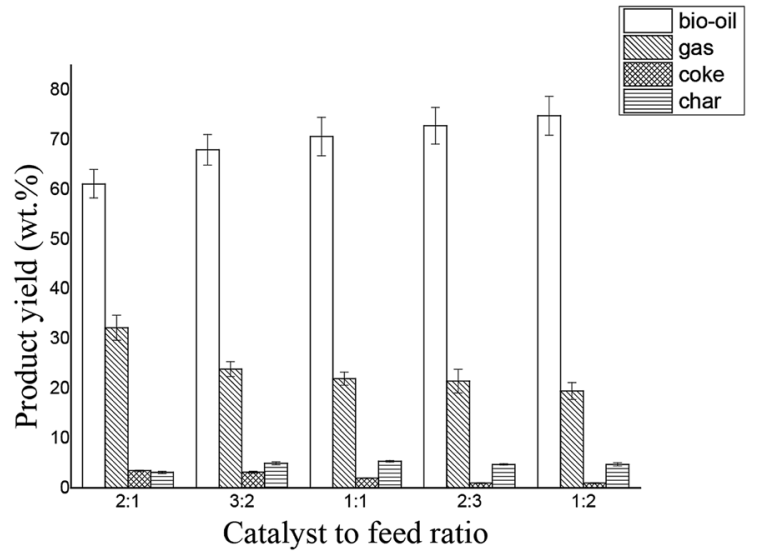

Fig. 5 (a) Product yields under different catalysis; (b) product yields with SiC-MCM41 under different catalytic temperature (c) product yields with SiC-MCM41 under different catalyst to feedstock ratio.

\subsection{Analysis of bio-oil characteristics}

Generally, the liquid product obtained from pyrolysis contains mainly aliphatic hydrocarbons, aromatics and oxygencontaining substances. The aliphatic hydrocarbons are classified into gasoline fraction $\left(\mathrm{C}_{5}-\mathrm{C}_{12}\right.$ hydrocarbons) and diesel fraction $\left(\mathrm{C}_{12+}\right.$ hydrocarbons) while mono-aromatics and polyaromatics consist of aromatic hydrocarbons. Fig. 6(a) illustrated the influence of no-catalyst and different catalysts on the liquid product chemical composition. As depicted in Fig. 6(a), The contents of $\mathrm{C}_{5}-\mathrm{C}_{12}$ hydrocarbons, $\mathrm{C}_{12+}$ hydrocarbons, mono-aromatics, poly-aromatics, and oxygen-containing compounds in bio-oils without catalysts were $15.06 \%, 10.70 \%$, $49.41 \%, 5.66 \%$ and $19.72 \%$, respectively. The MCM41 represents the deoxygenation and cracking capacity as the previous studies mentioned. ${ }^{\mathbf{1 3 , 1 5 , 2 0}}$ The $\mathrm{C}_{5}-\mathrm{C}_{12}$ hydrocarbons increased to $49.35 \%$ while the mono-aromatics, poly-aromatics, and oxygencontaining compounds decreased to $7.072 \%, 34.05 \%, 0.72 \%$ and $8.808 \%$, respectively. Li et al. ${ }^{20}$ clearly stated that the MCM41 have larger pore size, allowing the entrance of large molecules into the pores and converted into small molecules subsequently. Thus the oxygen-containing compounds and the long chain hydrocarbons decreased and the $\mathrm{C}_{5}-\mathrm{C}_{12}$ hydrocarbons increased. Under the catalysis of the SiC, the content of mono-aromatics were $51.92 \%$ and poly-aromatics were $16.984 \%$ which indicated the SiC obviously promote the formation of the aromatics, the oxygen-containing compounds reduced to 9.79\%. At the same time, a slight increase (4.66\%) was observed on the content of $\mathrm{C}_{5}-\mathrm{C}_{12}$ hydrocarbons. Further, by the observation of the variation of the bio-oil component, the composite catalyst combines the catalytic properties of SiC and MCM41. The proportion of $\mathrm{C}_{5}-\mathrm{C}_{12}$ hydrocarbons and mono-aromatics were $32.428 \%$ and $41.098 \%$, which were between the content of the bio-oil obtained from these two individual catalysts. The $\mathrm{C}_{12+}$ hydrocarbons decreased to $4.80 \%$ and the oxygencontaining compounds decreased to $19.24 \%$. The SiC/MCM41 catalytic effect is not as outstanding as that of composite catalysts. Compared with the group catalyzed by SiC-MCM41, the oxygen-containing compounds and the poly-aromatics increased by $1.24 \%$ and $3.8 \%$, respectively. Both of these two products were not we desired, the other components were between the value catalyzed by SiC and MCM41 and that was what we expected.

The effect of catalytic temperature on the chemical selectivity was conducted and described in Fig. 6(b). It can be observed that the $\mathrm{C}_{12+}$ hydrocarbons and mono-aromatics decreased $4.63 \%$ and $15.67 \%$ respectively while the $\mathrm{C}_{5}-\mathrm{C}_{12}$ hydrocarbons increased from $20.31 \%$ to $32.43 \%$ when the temperature increased from $250{ }^{\circ} \mathrm{C}$ to $400{ }^{\circ} \mathrm{C}$. This phenomenon happened mainly due to higher catalytic temperature facilitate the conversion from long carbon chain substance to gasoline fraction. ${ }^{34}$ Interestingly, the $\mathrm{C}_{5}-\mathrm{C}_{12}$ hydrocarbons decreased $12.06 \%$, the mono-aromatics increased $5.21 \%$ and the polyaromatics increased $2.37 \%$ when the temperature increased from 400 to $500{ }^{\circ} \mathrm{C}$. With further enhanced catalytic temperature, the bonds of long-chain hydrocarbons broken and shortchain hydrocarbons generated such as light olefin which are reactants for the Diels-Alder reaction, thus the aromatics increased. Fan et al. $^{\mathbf{2 6}}$ also found that the pyrolysis further enhanced with the higher catalytic temperature, resulting the decomposition of the $\mathrm{C}_{5}-\mathrm{C}_{12}$ hydrocarbons and the formation of aromatics, which was different from the result we obtained at present. This mainly was due to the different selectivity of different catalyst. At the same time, an increasing catalytic temperature improved the formation of oxygen-containing substances, which increased from 11.94 to $21.96 \%$. However, we choose $400{ }^{\circ} \mathrm{C}$ as the optimal temperature because both the $\mathrm{C}_{12+}$ hydrocarbons and mono-aromatic appeared a turning 
(a)
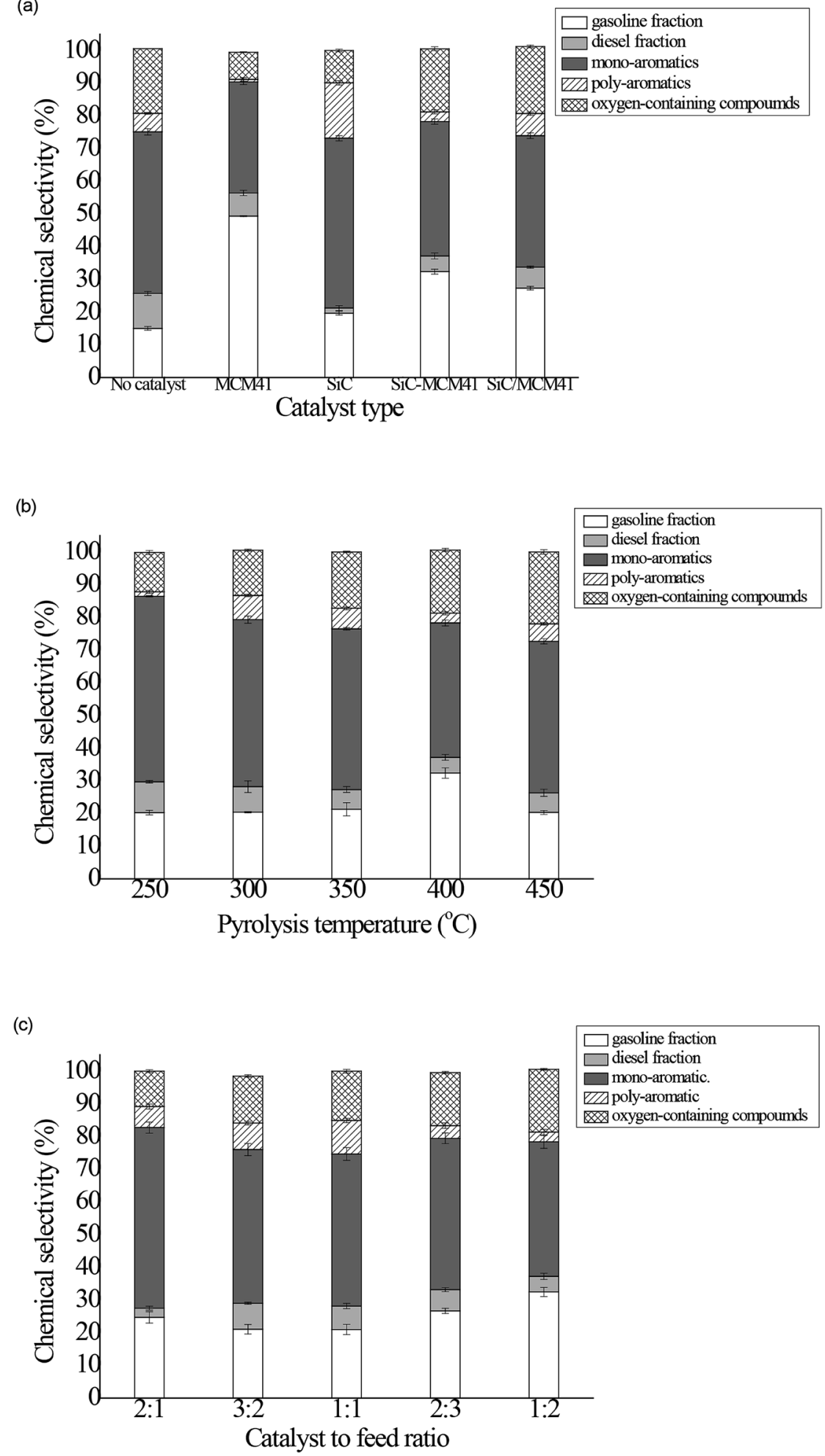

Fig. 6 (a) Bio-oil on chemical selectivity under different catalysis; (b) bio-oil on chemical selectivity with SiC-MCM41 under different catalytic temperature; (c) bio-oil on chemical selectivity with SiC-MCM41 under different catalyst to feedstock ratio.

point and the highest yield of $\mathrm{C}_{5}-\mathrm{C}_{12}$ hydrocarbons was obtained at this condition.

Fig. 6(c) shows the detailed chemical distribution for aromatic and hydrocarbons obtained from the catalytic pyrolysis at different catalyst to feed ratio. From the picture, when the catalyst to feed ratio increased from $1: 2$ to $2: 1$, the oxygencontaining compounds gradually decreased from $19.24 \%$ to $10.843 \%$. Conclusion could be drawn that with increasing of the catalyst ratio, the deoxygenation reaction enhanced during the pyrolysis. This phenomenon happened because the composite 
catalyst conserved the catalysis of MCM41 which is consistent with the study before. ${ }^{15}$ The mono-aromatics increased from $41.10 \%$ to $55.23 \%$ because the Sapium sebiferum kernel oil contains lots of unsaturated fatty acids which facilitate the cracking of carbonic chain, cycling reactions, therefore caused a subsequent aromatization and the increase of aromatics. ${ }^{24}$ The poly-aromatics increased from $2.98 \%$ to $10.31 \%$ initially like the mono-aromatics. However it decreased to $6.46 \%$ at the ratio of $2: 1$ mainly due to the strong ability of cracking carbon bonds. The $\mathrm{C}_{5}-\mathrm{C}_{12}$ hydrocarbons content first decreased to $20.94 \%$ at the ratio of $1: 1$, this mainly because the aromatization was more intense than bond breaking reaction. At the

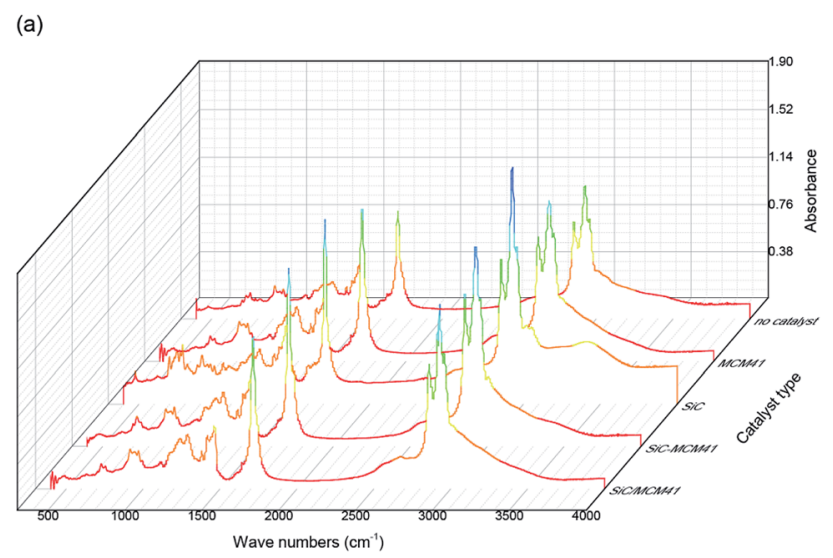

(b)

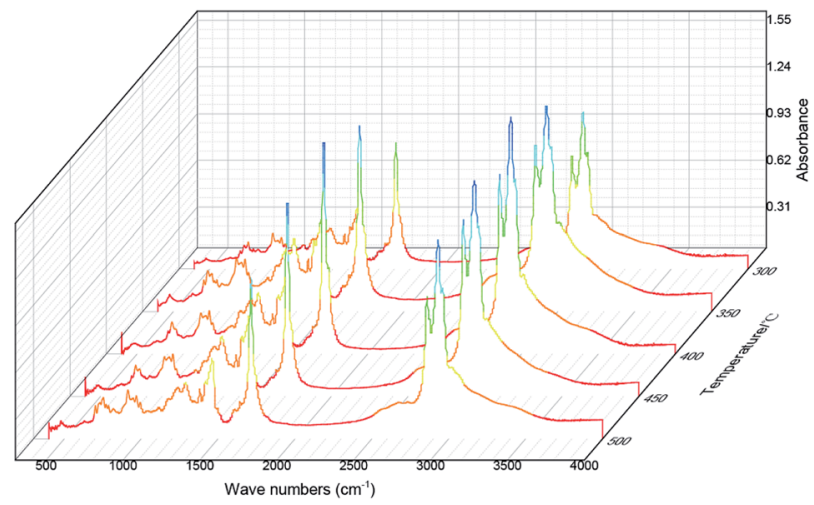

(c)

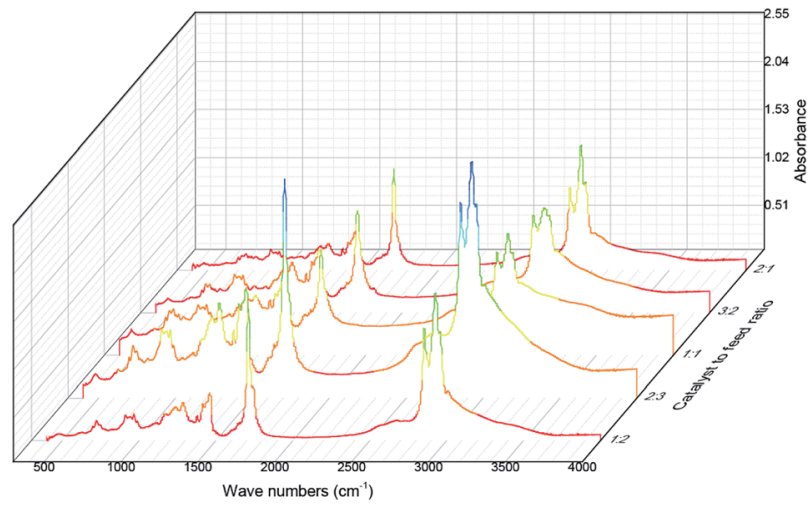

Fig. 7 (a) FTIR of bio-oil under different catalysis; (b) FTIR of bio-oil with SiC-MCM41 under different catalytic temperature; (c) FTIR of biooil with SiC-MCM41 under different catalyst to feedstock ratio. ratio of $2: 1$, the $\mathrm{C}_{5}-\mathrm{C}_{12}$ hydrocarbons have risen to $24.66 \%$. This reflects that the carbon chain rupture enhanced with increasing catalyst. On the other hand, the $\mathrm{C}_{12+}$ hydrocarbons first increased from $4.80 \%$ to $7.93 \%$, then deceased to $2.81 \%$ at the catalyst to feed ratio of $2: 1$. Results show that the $\mathrm{C}_{12+}$ hydrocarbons represent the contrary tendency of $\mathrm{C}_{5}-\mathrm{C}_{12}$ hydrocarbons which is a side validation of our view.

\subsection{FTIR analysis of bio-oil}

Fig. 7(a) shows the variation of the functional groups of bio-oil under different catalytic conditions. From the picture, results showed that different catalysts reflected different selection. Table 3 shows the functional groups of IR spectrometry of biooil derived from pyrolysis. At 2925 and $2856 \mathrm{~cm}^{-1}$, the peaks were corresponded to the aliphatic $\mathrm{C}-\mathrm{H}$ stretching vibration, the peak strength of the bio-oil catalyzed by the composite catalyst and mixed catalyst is between the other two catalysts. Same phenomenon also happened in the peaks at $1460 \mathrm{~cm}^{-1}$ corresponded to aromatic $\mathrm{C}-\mathrm{C}$ ring stretching. These phenomena indicated that the compound catalyst and mixed catalyst neutralized the two kinds of catalytic performance. As depicted in Fig. 7(b), At the catalytic temperature of $400{ }^{\circ} \mathrm{C}$, it's pretty obvious that the peaks at 2925 and $2856 \mathrm{~cm}^{-1}$ were larger than those in the other groups which indicated that higher proportion hydrocarbons in bio-oil. Thus we choose the $400{ }^{\circ} \mathrm{C}$ as the catalytic temperature. As for Fig. 7(c), though a similar trend was observed in peaks at 2925 and $2856 \mathrm{~cm}^{-1}$ at the condition of catalyst to feed ratio $2: 3$, the peaks area at $1710 \mathrm{~cm}^{-1}$ and $1290 \mathrm{~cm}^{-1}$ were larger than other groups which indicated that there were more oxygen-containing compounds in bio-oil. Instead, the bio-oil under the catalyst to feed ratio of $1: 2$ showed outstanding advantages in peaks aforementioned.

\subsection{Stability of catalyst}

The sustainability of catalyst was carried at the condition of the catalytic temperature $400{ }^{\circ} \mathrm{C}$ and the catalyst to feed ratio $1: 2$. The composite catalyst was used nine times continuously without baking activation. Fig. 8(a) shows the variation of the product distribution after 9 times use. From the picture, it is obvious that the product distribution is stable after multiple uses. The yield of the bio-oil floated between $72 \%$ and $75 \%$ while the difference between maximum and minimum gas production is only $3.53 \%$. The yield of coke and char were basically stable at $1 \%$ and $3.5 \%$ respectively. As for the bio-oil

Table 3 Functional groups of IR spectrometry of bio-oil derived from pyrolysis

\begin{tabular}{lll}
\hline Functional group & Wave range $\left(\mathrm{cm}^{-1}\right)$ & Wave number $\left(\mathrm{cm}^{-1}\right)$ \\
\hline Aliphatic C-H & $3000-2800$ & 2925,2856 \\
stretching & & \\
C = O carbonyl group & $1850-1660$ & 1710 \\
Aromatic C-C ring & 1600,1580, & 1460 \\
stretching & 1500,1450 & \\
C-O stretching & $1300-1000$ & 1290
\end{tabular}


(a)

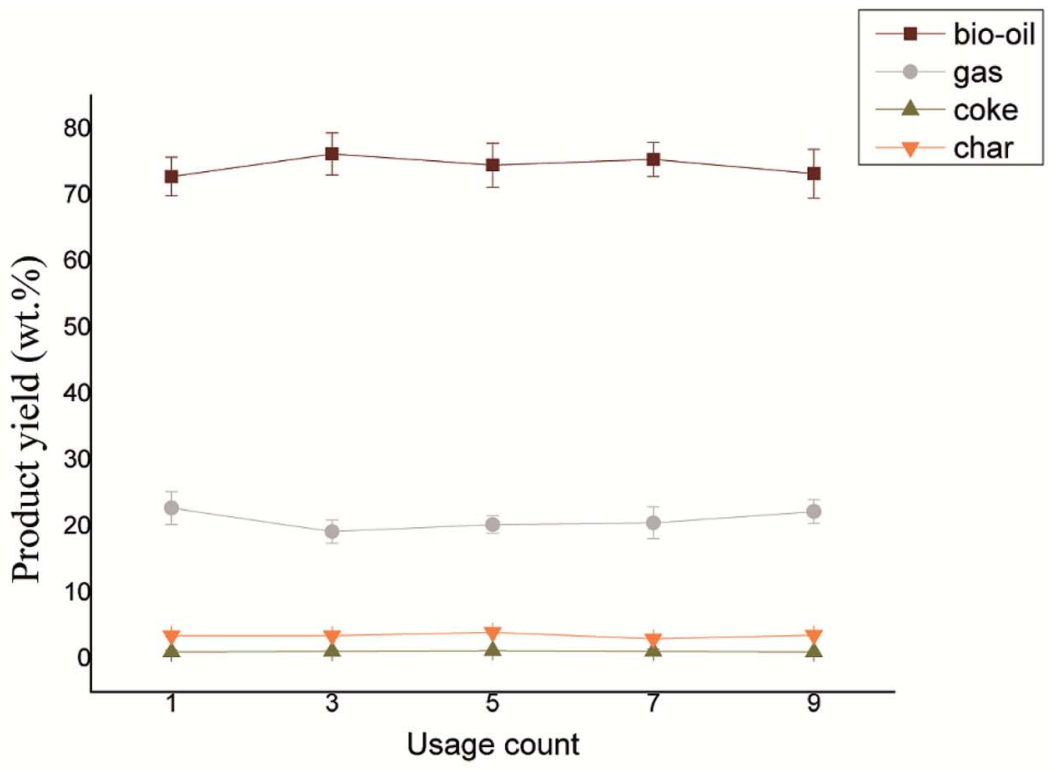

(b)

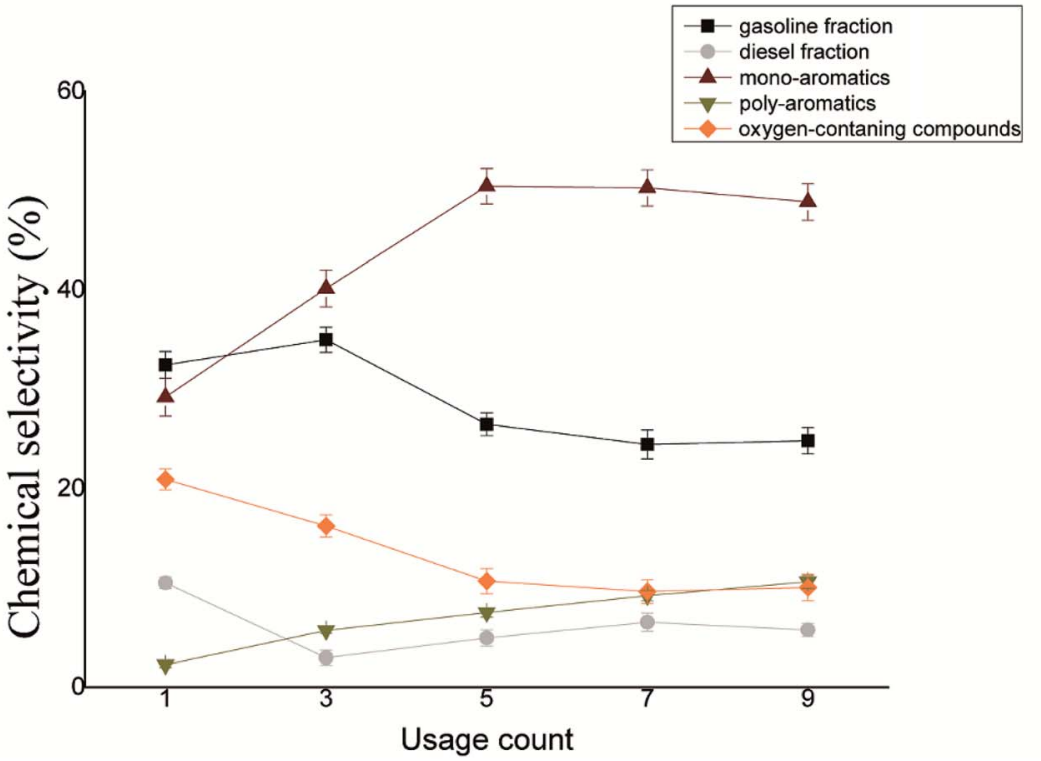

Fig. 8 Sustainability of catalyst (a) product yields variation with SiC-MCM41 after repeated use; (b) bio-oil composition with SiC-MCM41 variation after repeated use.

composition, some changes can be observed in the Fig. 8(b). It is interesting that the oxygen-containing compound decreased from $20.93 \%$ to $9.613 \%$ after 7 times use which confirmed that the deoxidization performance of catalyst was enhanced. At the same time, the mono-aromatics and the poly-aromatics both increased $21.06 \%$ and $8.36 \%$ respectively while the $\mathrm{C}_{5}-\mathrm{C}_{12}$ hydrocarbons deceased from $37.14 \%$ to $24.42 \%$ after 7 times use. We consider that after several times, the small molecules blocked the MCM41 pore, but the catalysts were not activated by torrefaction. However, the extraordinary the thermal stability of the SiC appeared. The components of bio-oil were increasingly similar to that under SiC catalysis alone especially the proportion of mono-aromatics. At the ninth use, the catalytic effect tends to be stable. But it appeared higher $\mathrm{C}_{5}-\mathrm{C}_{12}$ hydrocarbons
(24.79\%), $\mathrm{C}_{12+}$ hydrocarbons $(5.75 \%)$ and less polyaromatics $(10.60 \%)$ in contrast with the group of only SiC catalyzes.

\section{Conclusion}

Microwave assisted SiC-MCM41 composite catalyst for hydrothermal synthesis was developed in this study. The MCM41 represented the deoxygenation and cracking capacity that the $\mathrm{C}_{5}-\mathrm{C}_{12}$ hydrocarbons increased by $34.29 \%$ and the oxygencontaining compounds decreased by $10.91 \%$ in bio-oil. The composite catalyst combined the catalysis of SiC and MCM41 which increased the $\mathrm{C}_{5}-\mathrm{C}_{12}$ hydrocarbons and decreased the oxygen-containing compound. Results showed that the composite catalyst combined the catalytic effect of $\mathrm{SiC}$ and 
MCM41. With the further increasing of the catalytic temperature, the bio-oil yield decreased from $76.28 \%$ to $69.25 \%$. At the condition of catalytic temperature $400{ }^{\circ} \mathrm{C}$ and catalyst to feed ratio $1: 2,32.43 \% \mathrm{C}_{5}-\mathrm{C}_{12}$ hydrocarbons and $41.10 \%$ monoaromatics were obtained. The FTIR shows the variation in the amount of functional groups which is consistent with the results of GCMS. Furthermore, the sustainability of catalyst appeared well after several times use which retained the catalytic property.

\section{Conflicts of interest}

There are no conflicts to declare.

\section{Acknowledgements}

We gratefully acknowledge the financial support from the National Natural Science Foundation of China (No. 21766019), The Key Research and Development Program of Jiangxi Province (20171BBF60023), International Science \& Technology Cooperation Program of China (2015DFA60170), Science and Technology Research Project of Jiangxi Province Education Department (No. GJJ150213), Innovation and Entrepreneurship Development Fund of "Thousand talents program” Talent (No. 1001-02102082), Guangdong Provincial Key Laboratory of New and Renewable Energy Research and Development (No. Y707sb1001).

\section{References}

1 S. S. Lam, et al., Progress in waste oil to sustainable energy, with emphasis on pyrolysis techniques, Renewable Sustainable Energy Rev., 2016, 53, 741-753.

$2 \mathrm{~L}$. Wen, et al., Preparation of $\mathrm{KF} / \mathrm{CaO}$ nanocatalyst and its application in biodiesel production from Chinese tallow seed oil, Fuel, 2010, 89(9), 2267-2271.

3 Y.-y. Gao, et al., Optimization of transesterification conditions for the production of fatty acid methyl ester (FAME) from Chinese tallow kernel oil with surfactantcoated lipase, Biomass Bioenergy, 2009, 33(2), 277-282.

4 T. K. Phung, et al., Catalytic pyrolysis of vegetable oils to biofuels: catalyst functionalities and the role of ketonization on the oxygenate paths, Fuel Process. Technol., 2015, 140, 119-124.

5 E. Y. Emori, et al., Catalytic cracking of soybean oil using ZSM5 zeolite, Catal. Today, 2017, 279, 168-176.

6 Y. Wang, et al., Ex situ catalytic upgrading of vapors from fast microwave-assisted co-pyrolysis of Chromolaena odorata and soybean soapstock, Bioresour. Technol., 2018, 261, 306312 .

7 Y. Wang, et al., Co-pyrolysis of microwave-assisted acid pretreated bamboo sawdust and soapstock, Bioresour. Technol., 2018, 265, 33-38.

8 I. Choedkiatsakul, et al., Integrated flow reactor that combines high-shear mixing and microwave irradiation for biodiesel production, Biomass Bioenergy, 2015, 77, 186-191.
9 D. Crudo, et al., Biodiesel production process intensification using a rotor-stator type generator of hydrodynamic cavitation, Ultrason. Sonochem., 2016, 33, 220-225.

10 S. S. Lam, et al., Pyrolysis using microwave absorbents as reaction bed: an improved approach to transform used frying oil into biofuel product with desirable properties, $J$. Cleaner Prod., 2017, 147, 263-272.

$11 \mathrm{H}$. Lee, et al., Catalytic hydrodeoxygenation of Geodae-Uksae pyrolysis oil over Ni/desilicated HZSM-5, J. Cleaner Prod., 2018, 174, 763-770.

$12 \mathrm{~L}$. Li, et al., Preparation of basic mesoporous molecular sieves $\mathrm{K} 2 \mathrm{O} / \mathrm{Mg}-\mathrm{MCM}-41$ and its catalytic performance on the cracking of soybean oils, J. Anal. Appl. Pyrolysis, 2014, 110, 313-317.

13 D. Wang, et al., Comparison of catalytic pyrolysis of biomass with MCM-41 and CaO catalysts by using TGA-FTIR analysis, J. Anal. Appl. Pyrolysis, 2010, 89(2), 171-177.

14 A. Casoni, et al., Catalytic pyrolysis of cellulose using MCM41 type catalysts, Appl. Catal., A, 2016, 514, 235-240.

15 B. Zhang, et al., Conversion of poultry litter into bio-oil by microwave-assisted catalytic fast pyrolysis using microwave absorbent and hierarchical ZSM-5/MCM-41 catalyst, J. Anal. Appl. Pyrolysis, 2018, 130, 233-240.

16 R. Amrousse, et al., Deposition of mesoporous activated powder alumina on SiC ceramic foam substrates by an in situ hydrothermal technique, Powder Technol., 2013, 247, 231-234.

17 M. Nacken, et al., Development of a catalytic ceramic foam for efficient tar reforming of a catalytic filter for hot gas cleaning of biomass-derived syngas, Appl. Catal., B, 2012, 125, 111-119.

18 Y. Chen, et al., One-step ethanolysis of lignin into smallmolecular aromatic hydrocarbons over nano-SiC catalyst, Bioresour. Technol., 2017, 226, 145-149.

$19 \mathrm{Z}$. Yu, et al., Microwave-assisted catalytic pyrolysis of Chinese tallow kernel oil for aromatic production in a downdraft reactor, J. Anal. Appl. Pyrolysis, 2018, 133, 16-21.

$20 \mathrm{X}$. Li, et al., In situ catalytic upgrading of biomass-derived vapors using HZSM-5 and MCM-41: effects of mixing ratios on bio-oil preparation, J. Energy Inst., 2017, 92(1), 136-143.

21 G. Men, et al., Study on microwave synthesis and adsorption properties of MCM_41 mesoporous molecular sieve, Contemp. Chem. Ind., 2011, 40(4), 344-347.

22 K. Deekamwong, et al., Influence of gel composition and microwave-assisted hydrothermal time in MCM-41 synthesis, Mater. Chem. Phys., 2017, 201, 384-390.

23 L. Dai, et al., Production of bio-oil and biochar from soapstock via microwave-assisted co-catalytic fast pyrolysis, Bioresour. Technol., 2017, 225, 1-8.

24 A. M. d. M. Araújo, et al., Thermal and catalytic pyrolysis of sunflower oil using AlMCM-41, Renewable Energy, 2017, 101, 900-906.

$25 \mathrm{~F} . \mathrm{W}$. Yu, et al., Study on the pyrolysis of cellulose for bio-oil with mesoporous molecular sieve catalysts, Appl. Biochem. Biotechnol., 2012, 168(1), 174-182. 
26 Y. Zhao, et al., Fast microwave-assisted ex-catalytic copyrolysis of bamboo and polypropylene for bio-oil production, Bioresour. Technol., 2017, 249, 69-75.

27 M. Rehan, et al., Effect of zeolite catalysts on pyrolysis liquid oil, Int. Biodeterior. Biodegrad., 2017, 119, 162-175.

$28 \mathrm{X}$. Junming, et al., Liquid hydrocarbon fuels obtained by the pyrolysis of soybean oils, Bioresour. Technol., 2009, 100(20), 4867-4870.

29 F. C. Borges, et al., Fast microwave-assisted pyrolysis of microalgae using microwave absorbent and HZSM-5 catalyst, Bioresour. Technol., 2014, 166, 518-526.

30 D. Duan, et al., Ex situ catalytic co-pyrolysis of lignin and polypropylene to upgrade bio-oil quality by microwave heating, Bioresour. Technol., 2017, 241, 207-213.
31 L. Fan, et al., Ex situ catalytic upgrading of vapors from microwave-assisted pyrolysis of low-density polyethylene with MgO, Energy Convers. Manage., 2017, 149, 432-441.

32 L. Dai, et al., Microwave-assisted catalytic fast co-pyrolysis of soapstock and waste tire for bio-oil production, J. Anal. Appl. Pyrolysis, 2017, 125, 304-309.

33 L. Fan, et al., In situ and ex situ catalytic upgrading of vapors from microwave-assisted pyrolysis of lignin, Bioresour. Technol., 2018, 247, 851-858.

34 K. Wang, P. A. Johnston and R. C. Brown, Comparison of in situ and ex situ catalytic pyrolysis in a micro-reactor system, Bioresour. Technol., 2014, 173, 124-131. 